\title{
ACREDITACIÓN UNIVERSITARIA
}

\author{
Dr.JorgeSilva Merino
}

\section{RESUMEN}

El presente artículo aborda el tema de la acreditación como resultado de la validación de la evaluación externa, cuyo fin es conducir a la institución universitaria a la aplicación de un programa de mejoramiento institucional. El punto de partida de ese proceso es la autoevaluación que dinamiza procesos de planeación e investigación con una racionalización de todoslos componentes afin de asegurar que las políticas y normas educativas aseguren el mejoramiento de la calidad .

\section{ABSTRACT}

The present article is about the accred it at ion as a result of a quality assurance process from the externa! evaluation, which purpose is to lead the university instit ut ion int o the application of an instit ut ional imp rovement program. The starting point of this process is the s lf - evaluation which reinforce process of research and planning with a rationalization of ali the components in order to assure that educational policies and regulations will guarantee the qua lity imp rovement .

\section{PALABRAS CLAVE}

Acreditación, calidad educativa, programa académico, programa de me joram iento, evaluac ión.

\section{KEYWORDS}

Accreditation, educative quality, academic program, imp rovement program, eva luat ion.

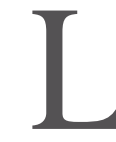
a calidad de la educación en el Perú tiene sustento legal en los artículos N 3, 14, 15 y 16 de la Ley NQ28044, Ley General de Educación.

A estas normas se agrega el artículo N 51 de la citada ley, que establece textualmente, lo siguiente: "Las insti tu ciones un iversitarias, así como los institutos, escuelas y otros centros que imparten Educación Superior pueden ser públicos o privados y se rigen por ley específica". De otro lado, el 19 de mayo de 2006, el Congreso de la República ordenó que se publique y cumpla la Ley N 28740, Ley del Sistema Nacional de Evaluaci ón, Acreditación y Certificación de la Calidad Educativa, cuyo artículo NQ 2 define el SINEACE, en los términos: "El Sistema Nacional de Eval uación, Acreditación y Certificación de la Calidad Educativa es el conjunto de organismos, normas y p rocedimien tos estr uct uradose integrados funciona lmente, destinados a definir y establecer los criterios, estándares y p rocesos de evaluación, acreditación y certificación a fin de asegurar los niveles básicos de calidad que deben brindar las instituciones a las qu e se refiere la Ley General ele Educación NQ 28044,y promover su desarrollo cualitativo. (El subrayado es nuestro)

Con este propósito, el sistema está conformado por órganos operadores que garantizan la indepen dencia,imparcialidad e idoneidad ele los procesos ele evaluación, acreditación y certifica ción.

La eval uación e.'-'á a cargo de las entidades especializadas nac ion ales o in tern aci on ales , reconocidas y registrad as $\mathrm{p}$ ar a realizar las 
evaluaciones con fines de acreditación y por instituciones públicas cuando corresponda".

Las normas citadas deberán ser concordadas e interpretadas,si fuere el caso, en el marco de la norma Constitucional, la misma que en su artículo NQ 18 determina lo siguiente: "La educación universitaria tiene como fines la formación profesional, la difusión de la cultura, la creación intelectual y artística y la investigación científica y te cnológica. El Estado garantiza la libertad de cátedra y rechaza la intolerancia...

La universidad es autónoma en su régimen normativo, de gobierno, académico, administrativo y económico. Las universidades se rigen por sus propios estatutos en el marco de la Constitución y de las leyes".

En el orden jerárquico de las leyes, no debemos olvidar que las universidades se rigen por la Ley Universitaria y por sus estatutos. Precisamente, la referida ley en su artículo NQ 1 reafirma lo ya establecido por la Constitución, al afirmar que "las universidades tienen autonomía académica, normativa y administrativa dentro de la ley". A esta disposición se agrega otra que protege la autonomía respecto a la naturaleza de los títulos que ellas otorgan a Nombre de la Nación: "Solo las universidades otorgan los grados académicos de Bachiller, Maestro y Doctor. Además, otorgan, en Nombre de la Nación, los títulos profesionales de Licenciado y sus equivalentes que tienen denominación propia, así como los de segunda especialidad profesional..."

En otro ámbito de ideas, cuando hablamos de acreditación de la calidad del servicio educativo universitario, tenemos que referirnos a los programas académicos, escenarios reales donde se realiza la acción educativa; es decir; el proceso de enseñanzaaprendízaje, en función de su propia concepción acerca de este proceso y conforme a su modelo educativo diseñado. El mejoramiento del proceso de enseñ anz a- ap rendiz aje, piedra angular de la formación profesional, una de las funciones básicas de la universidad, pasa por su evaluación integral y sistemática, de modo que su análisis y valoración considere la articulación con variables de otros factores concomitantes; proceso muy complejo y a la vez muy singular en cada universidad, que no resiste el encasillamiento o sometimiento a referentes únicos ygeneralizados.

Las leyes peruanas garantizan a la universidad, libertad para la investigación científica, sin la cual ésta no habría podido ofrecer el conocimiento para el desarrollo social y económico del país, junto a esta libertad tiene otras prerrogativas como la libertad de cátedra, la cátedra paralela yla cátedra libre.

El norte o preocupación central es el mejoramiento de la calidad que, tratándose de la educación superior, UNESCO (1998) afirmaba que "Calidad es la adecuación del Ser y Quehacer de la Educación Superior a su Debe Ser". Esta concepción, que parece restringir su óptica a los límites internos institucionales, debe verse completada con laidea de inclusión social que tome en cuenta la necesidad ele su pertinencia contextual.

El nivel de calidad se pone de relieve con la autoevaluacíón y su validación necesaria a través de la evaluación externa, a fin de evitar enfoques unilaterales que impiden la amplitud de la reflexión. Este esfuerzo no tendría mayor importancia si es que no conduce a las universidades, en forma libre y autónoma, a tomar conciencia ele sus fortalezas y debilidades, como plataforma real para formular y llevar a efecto un programa de mejoramiento tanto de su calidad institucional como de su servicio en términos de formación profesional, investigación, extensión y proyección social.

El programa ele mejoramiento de la calidad institucional ele cada universidad como de los servicios que presta, implica una respuesta libre y flexible pero, al mismo tiempo, responsable, ligada necesariamente a su historia institucional y a sus posibilidades. Es una respuesta a sí misma y a la sociedad para la que existe yse debe.

Cuando este programa de mejoramiento no sólo se orienta a la propia superación universitaria como institución, sino también a la de sus programas académico-profesionales, con fines de acreditación, verá facilitado el proceso ele autoevaluación si los referentes de los juicios de valor son pertinentes a la realidad histórico-social de cada universidad; más por el contrarío, sí estos referentes son "camisas de fuerza", uniformes para todas las instituciones, la autoevaluación y la acreditación, no sólo retardarán su ejecución, sino, lo que es peor, invitará a forzar resultados con el consiguiente atentado contra la objetívíclacl, transparencia y honestidad.

Desde que en los años setentas se reflexionaba sobre la evaluación, ya se avizoraba uno de sus peligros y desviaciones: considerar a la evaluación como instrumento de poder, alejándola de su papel de

\section{1 un1Fé}


medio al servicio del mejoramiento dela calidad de la educación; es de esperar que no se repita la historia. Todavía estamos a tiempo de enmendar rumbos, flexibilizandolos términos, referentes y el proceso de autoevaluac ión acreditación.

Tarea difícil resulta conciliar el respeto a la autonomía universitaria con la necesidad de garantizar en todas las universidades, niveles de calidad de dimensión nacional e internacional. En verdad no sería muy difícil encontrar una fórmula sabia para salir de la encrucijada. El primer gran paso sería tomar conciencia de que los desniveles de desarrollo y precariedad institucional de algunas universidades, es consecuencia de medidas populistas como la creación de universidades para enfrentar presiones sociales o pagar el apoyo político durante procesos electorales. Las universidades son el reflejo de estos fenómenos, pero también del ritmo y nivel de desarrollo de sus propios contextos territoriales, sociales, económicos y culturales. Hay quienes creen que la institución universitaria debe estar al margen de estas consideraciones y, por tanto, su evaluación y acreditación no las debe tomar en cuenta. Esta es una posición simplista y de espaldas a la realidad. Se dice: No importa cómo, pero hay que estandarizar larealidad.

Como corolario de las reflexiones en torno a la autoevaluación orientada a la acreditación, cada vez, se ve con más claridad la necesidad de priorizar la atención por el fomento de la cultura del mejoramiento continuo de la calidad de la educación universitaria. Esta preocupación pasa por enfrentar dos niveles de atención del trabajo universitario:

En primer lugar, la impostergable necesidad de vincular y centralizar los procesos de evaluación, planeación y de investigación, con la creación y puesta en funcionamiento de un órgano integrador y con suficiente presupuesto, encargado de procurar niveles crecientes de calidad institucional y de los servicios educativos. A este órgano correspondería articular las funciones de planificación, investigación y evaluación, de modo que no sigan comportándose como carriles independientes sino que su articulación potencie sus resultados con una mayor racionalización de sus presupuestos e infraestructuras; pero lo que es más importante, apunta a que este órgano institucional sería el encargado de dirigir las políticas y normas que aseguren el quehacer universitario hacia el mejoramiento continuo delacalidad universitaria.

En segundo lugar, poner énfasis en perfeccionar los perfiles de ingreso o nombramiento de los docentes universitarios, así como su evaluación y mejoramiento continuo, dado que ellos son la única garantía de la calidad del servicio educativo universitario.

Dr.Jorge Silva Merino

Doctor en Educación y Abogado. Fue Director General de Educación Superior. En la UNIFÉ ha sido Director de la Oficina de Evaluación, Jefe del Departamento de Educación, Decano de la Facultad de Ciencias de la Educación y Vicerrector Administrativoj actualmente, continúa como docente en la Escuela de Posgrado. Es autor de artículos sobre educación. 